\title{
Propagation Lifetime from the Surface and Internal Defects in the Ultra High Cycle Fatigue Regime
}

\author{
Yves Nadot
}

\author{
Laboratoire de Mécanique et de Physique des Matériaux, UMR CNRS 6617, ENSMA, 1 avenue Clément Ader, Téléport \\ 2, BP 40 109, 86961 Futuroscope cedex, France.
}

\begin{abstract}
Ultra High Cycle fatigue leads to a failure initiated in the bulk material of a material. Some results on the nodular cast iron are presented: initiation occurs from the defects, located at the surface or in the bulk. It has been shown that environment plays a major role that could explain the difference between fatigue lives, for the surface and internal initiation. The influence of the defect size and crack growth law is discussed and, the importance of fatigue crack initiation stage is revealed, in the ultra high cycle regime
\end{abstract}

Keywords: Casting, high cycle fatigue, environmental effect, defect.

\section{INTRODUCTION}

Over the traditional fatigue limit, fatigue failure can occur. This has been shown on different metallic materials [15], low and high strength steel, nodular cast iron or aluminium alloys. Results were obtained by using an ultrasonic frequency machine, and the influence of increase of temperature, and the load rate displacement or the non-uniform stress distribution, were involved to explain the difference of mechanisms. Experimental comparisons have been done with the classical tests: failure can occur below the fatigue limit for different materials and often from the bulk. This important result needs to be analyzed and understood in order to give the relevant tools, to the engineers. Initiation sites at the origin of the failure, in the giga cycle regime, can be extremely different: triple points at grain boundaries in very clean materials, non metallic inclusions smaller or bigger than the grain size and casting defects. The size as well as the morphology of these various populations of initiation sites, are also very different and vary from one micrometer to a few millimeters. From the last remark, it can be concluded that a relevant engineering approach to calculate fatigue life of the components in the giga cycle regime, needs a careful investigation of the material and its fatigue behaviors.

We will focus our attention on the defect containing materials with a defect size bigger than the microstructure. This is the case for casting materials, and the materials impacted in service by foreign object or corrosions pits. The first part of this paper presents fatigue mechanisms for defective materials. The environmental effect on the fatigue life in relation with the position of the defect is also discussed. The influence of defect size on the fatigue life is studied and the last part proposes a crack growth law, used to calculate the fatigue life. The conclusion gives some arguments to show

*Address correspondence to this author at the Laboratoire de Mécanique et de Physique des Matériaux, UMR CNRS 6617, ENSMA, 1 avenue Clément Ader, Téléport 2, BP 40 109, 86961 Futuroscope cedex, France;

E-mail: yves.nadot@lmpm.ensma.fr the importance of environment for the internal fatigue failure and reveals the importance of the initiation stage, often neglected for flawed materials.

\section{FATIGUE MECHANISMS IN THE GIGA CYCLE REGIME}

Fatigue mechanisms are dependent on the parameters such as material (structure and composition), mechanical loading and environment. We proposed to divide the fatigue mechanisms in different stages as shown in Fig. (1). During stage A, cyclic deformation occurs in the bulk and at the surface, it is basically a dislocation mechanism (hardening or softening as shown by Mughrabi [6,7]) and it can be associated with micro-damage at the surface or in the bulk (non propagating cracks observed below the fatigue limit [8]). During stage $\mathrm{B}$, the propagation of the macroscopic surface crack leads to the failure in domain $\mathrm{C}$, where the sample breaks from the surface. The same basic mechanism is proposed for internal initiation. Stage $\mathrm{A}^{\prime}$ is similar to stage A, with a difference between surface and bulk. Furthermore, the cyclic deformation is not homogeneously distributed but very localized in some grains, because the stress is very low. Stage B' corresponds to the propagation of a macroscopic crack from an internal defect: the damage is not enhanced by the ambient air and leads to the failure of the sample in domain $C^{\prime}$ from the bulk. Stage D is the stress level below which the material remains perfectly elastic even at a microscopic level and no micro damage appears. The transition between surface and internal failure is dependent on the material, environment and loading, so that the position of point $\mathrm{O}$ is not constant. We can characterize this transition by a stress level, called $\sigma_{\text {trans. }}$. For example, reference [9] shows a stress transition from the surface to the internal initiation, in clean titanium alloys with a lifetime of about $10^{5}$ cycles, while high strength steel shows this transition with a lifetime of about $10^{8}$ cycles [1]. Fig. (1) is a general fatigue failure map that can be different for different material; e.g. stage A may be negligible for brittle materials, while it can be very important for ductile ones. 


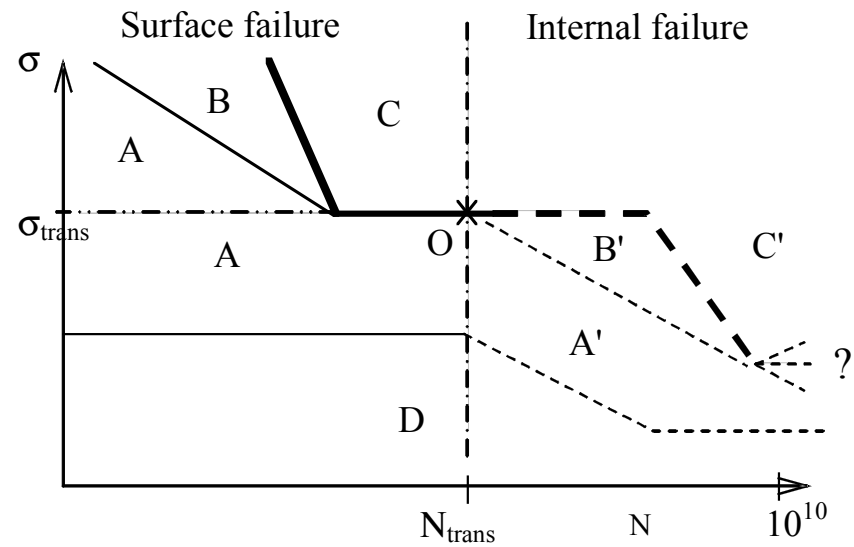

Fig. (1). General fatigue mechanism map. $\sigma(\mathrm{MPa})$ versus $\log (\mathrm{N})$.

It is important to draw the fatigue mechanism map for the defect containing materials. Two materials have been fatigued close to the fatigue limit: a nodular cast iron containing natural defects and a C 35 carbon steel containing artificial defects. The two materials have been tested in many different conditions with a careful observation of damage at the tip of the defect, for different sizes and geometries of defects [10-14]. Fig. (2) gives an illustration of two different behaviors. In nodular cast iron, non propagating cracks are observed below the fatigue limit (Fig. 2a). The NPC have been revealed by alternating environment during the fatigue loading (see $[10,11]$ for more details). Even if the length of the crack at the surface of the sample is important $(350 \mu \mathrm{m})$, the cracked area in the bulk is not so important as compared to the size of the defect, and the micro-crack does not encircle the defect, it seems therefore, difficult to consider the defect equivalent to a crack. Fig. (2b) shows the crack path of a crack, initiated at the tip of an artificial defect in a C 35 carbon steel. The conclusion of this study is that, fatigue mechanisms for the material containing artificial defects are similar to the defect free material; a micro-crack initiates from the tip of the defect in the maximum shear planes and is forced to propagate perpendicularly to the maximum principal stress direction due to the stress distribution around the defect (for more details see [13]). Consequently, it does not seem possible to conclude that materials with a defect, under fatigue loading, behave like brittle ones, a defect is not always equivalent to a crack and initiation can be similar to a defect free material. These two experiments show that it is not so easy to consider a defect equivalent to a crack, for flawed materials: mechanisms can be similar to the defect free materials.

In the next section, we will tend to understand the controlling parameters to evaluate the propagation fatigue life of defect containing samples, under fatigue loading. Propagation life during stages B and B' are calculated and results are discussed on the basis of environmental effect and defect size.

\section{ENVIRONMENTAL EFFECT}

Experimental data from Murakami [3] and Sakai [1] are used in this section to evaluate the use of damage crack growth law under air and vacuum to analyze the failure from the internal or surface defect. Figs. (3a) and (4a) are related to the data obtained on SCM 435 steel (tension loading at
$100 \mathrm{~Hz}$ ), containing internal non metallic inclusions [3]. The initial circular crack radius is $14 \mu \mathrm{m}$, which is equivalent to $\sqrt{\text { area }}=17 \mu \mathrm{m} . \Delta \mathrm{K}$ is calculated, using the appropriate value of the crack shape factor $\mathrm{Y}[15,16]$, and in case of an internal circular crack under tension (Fig. 3a), $\mathrm{Y}=2 / \Pi$. Samples are loaded under uni-axial tension with the load ratio $\mathrm{R}=-1$.

(a)

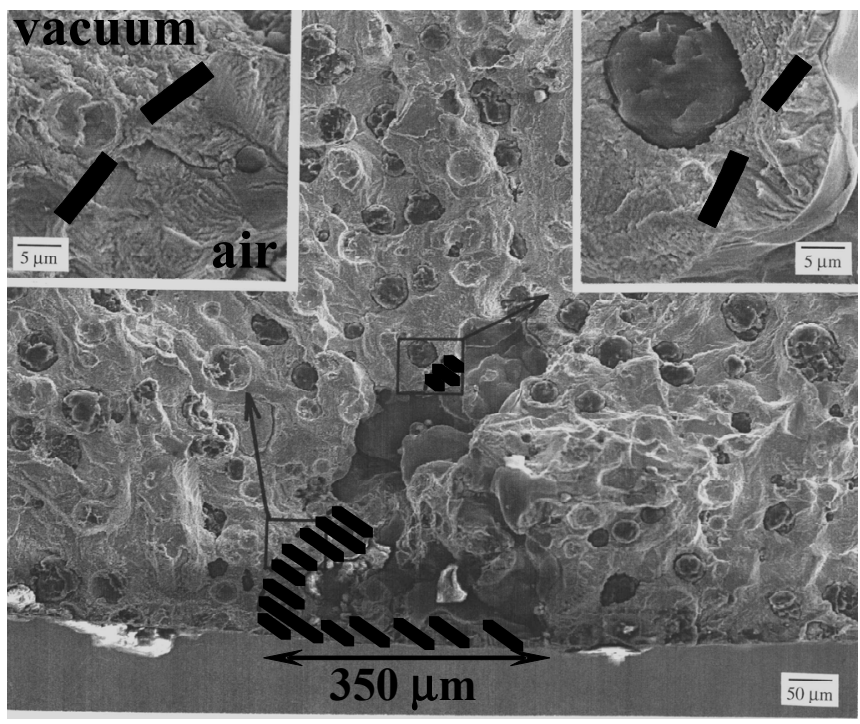

(b)

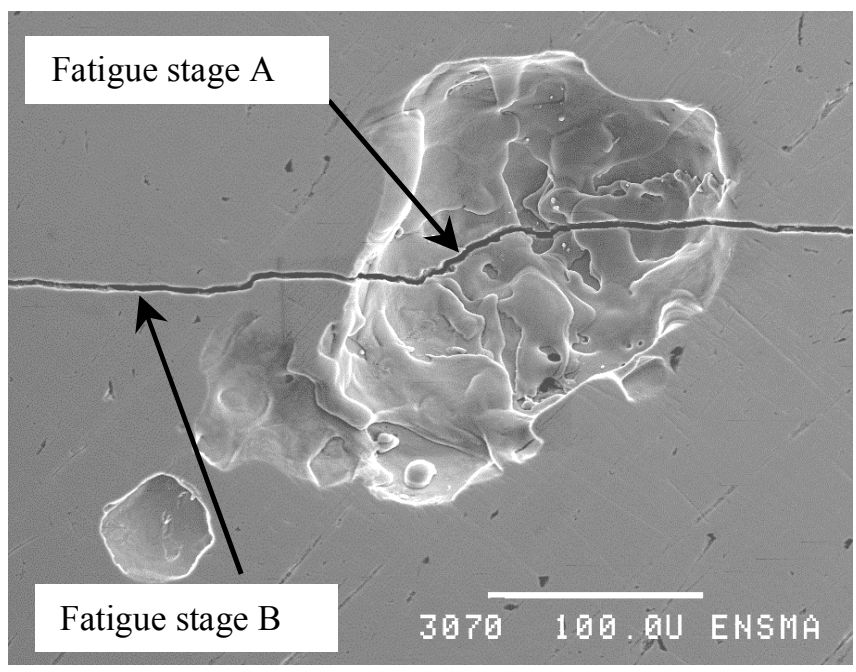

Fig. (2). (a) Non propagating crack below the fatigue limit revealed after failure under vacuum in nodular cast iron (fracture surface) [12] (b) Crack path in C 35 carbon steel containing artificial defect [13].

Figs. (3b,c) and (4b) relate to the data obtained on SUJ2 steel under flexion loading, containing surface and internal non metallic inclusions [1]. The initial crack radius is $5 \mu \mathrm{m}$ based on the defect size, given by the authors. The crack shape factor for a surface defect (Fig. 3b) integrates the stress gradient of the bending load [15]. In case of the sub surface initiation (Fig. 3c), the crack is considered circular, with a radius $5 \mu \mathrm{m}$, so the crack growth law under vacuum is used with a shape factor $2 / \Pi$ until the crack reaches the surface. In this case, the stress gradient under bending is taken 

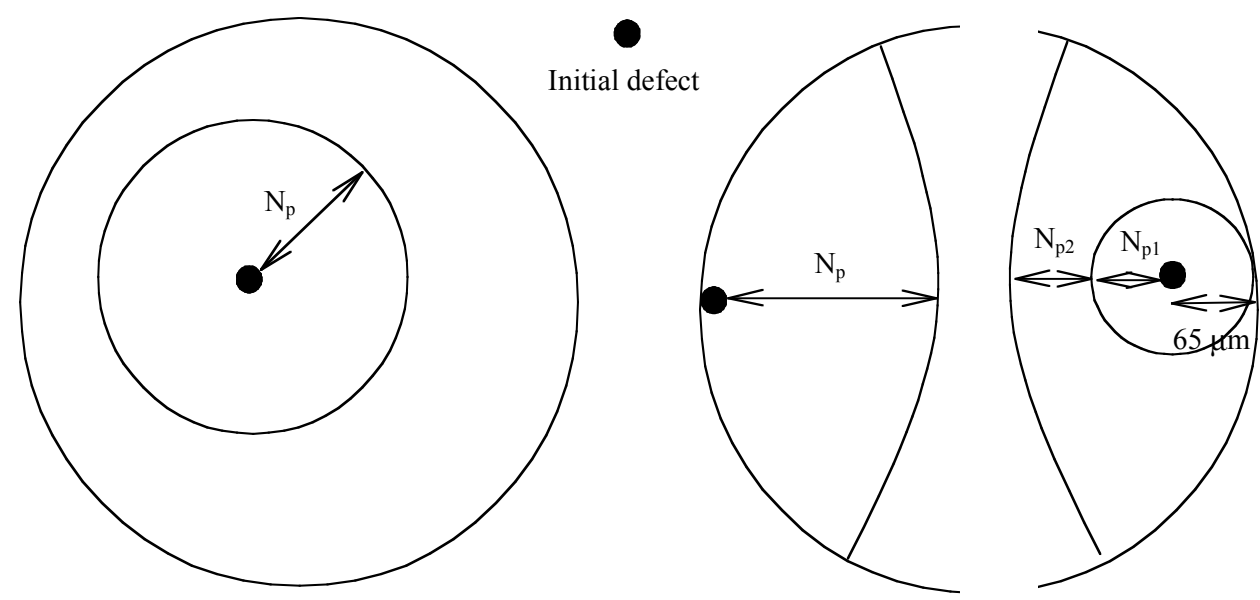

Fig. (3). Hypothesis for the calculation of propagation life (a) tension loading, internal defect (b) bending loading, surface defect (c) bending loading, subsurface defect.

into account by means of the calculated stress at the distance of the initial defect from the surface. When the crack reaches to the surface, a surface crack with a radius equal to the depth of the internal crack propagates from the surface under air with the appropriate shape factor, previously used for bending loading.

We then make the hypothesis that a natural crack propagates without crack closure. Therefore, the most appropriate crack growth law is the effective one. It is necessary to get the crack propagation effective behavior for steels, under air and vacuum. The work of Petit and Henaff [17-19] gives us the experimental effective Paris law for steels, under air and vacuum:

$\frac{d a}{d N}=C \Delta K_{e f f}^{m} \quad$ and $\quad \Delta K=Y \Delta \sigma \sqrt{\Pi a}$

AIR

$$
\mathrm{C}=1.410^{-12}
$$$$
\mathrm{m}=3.86 \Delta K_{t h}=3 \operatorname{MPa} \sqrt{m}
$$

VACUUM $\mathrm{C}=1.410^{-13}$

$$
\mathrm{m}=4 \quad \Delta K_{t h}=5 \operatorname{MPa} \sqrt{m}
$$

In Fig. (4), four parameters have to be considered for the discussion of the results : crack shape, stress level and stress gradient, crack closure and environment.

- The crack shape does not effectively influence the results: the comparison between constant semicircular crack shape factor $\mathrm{Y}$ and iso-K crack shape factor, does not change more than $10 \%$ of the results.

- $\quad$ The stress level is important: for high stress level and short fatigue life, initiation stage A is very short. Indeed, the propagation life should describe nearly the whole fatigue life. Nevertheless, the hypothesis of Linear Elastic Fracture Mechanics must be checked before the use of $\Delta \mathrm{K}$.

- $\quad$ The stress gradient is useful to compare tension and bending tests: under bending, the propagation life is higher than tension, because the stress level is lower when the crack grows in the bulk. Nevertheless, this effect is not very important because the most important part of the lifetime concerns with the first stages of propagation over a short physical distance, so that the stress gradient is not so important.
- $\quad$ The load amplitude used for calculations is the positive part of the fatigue cycle, this hypothesis leads to an overestimation of the propagation life, because the closure level for a natural crack under load ratio $\mathrm{R}=$ 1 , can be negative, so that the actual effective stress amplitude controlling the propagation is higher than the one used for computations.

- Environmental effect is important for steel, because crack growth rates under vacuum are lower than under air.

Results obtained under tension for internal defects show that the crack growth law in air predicts very short propagation life as compared to the total fatigue life. The propagation life calculated with the vacuum law gives better results. For stress higher than $750 \mathrm{MPa}$ and fatigue lives shorter than 500,000 cycles, the propagation life is overestimated because the stress amplitude does not take into account the real closure level of natural cracks, as stated above. Below this value, predictions lead to the conclusion that propagation life is shorter than the total fatigue life.

Fig. (4b) shows similar results for surface defects: the use of the crack growth law in air, gives overestimated results for short fatigue lives and reveals the importance of the initiation stage for higher fatigue lives. For sub surface defects, the use of the vacuum law shows that initiation stage is not negligible in any case because propagation lives are always clearly lower than the total fatigue life.

This first result shows that it is necessary to consider the environmental effect for the assessment of propagation life to separate the surface, subsurface and internal failure. Furthermore, the initiation stage as defined in Fig. (1), is not negligible, whatever the type of defect location is in the ultra high cycle range. Nevertheless, it is necessary to perform sensitivity analysis in order to evaluate the accuracy of the previous results. The next section proposes to study the influence of the defect size and crack growth law on the propagation life assessment.

\section{INFLUENCE OF DEFECT SIZE AND CRACK GROWTH LAW}

In order to calculate the propagation life, the initial crack size is determined with the defect size. Fig. (5a) shows the 
evolution of the propagation life for internal defects from 5 to 50 microns, for stress level close to the fatigue limit, results vary from $10^{6}$ to $10^{7}$ cycles, and this difference is not negligible. Fig. (5b) shows similar behavior both for the surface and internal defects; a variation of the defect size from 2 to 20 microns leads to a significant evolution of the propagation life. Fig. (6) shows that the propagation life is not the main part of the total fatigue life, whatever is size of the defect, so that more attention should be given to stage A.
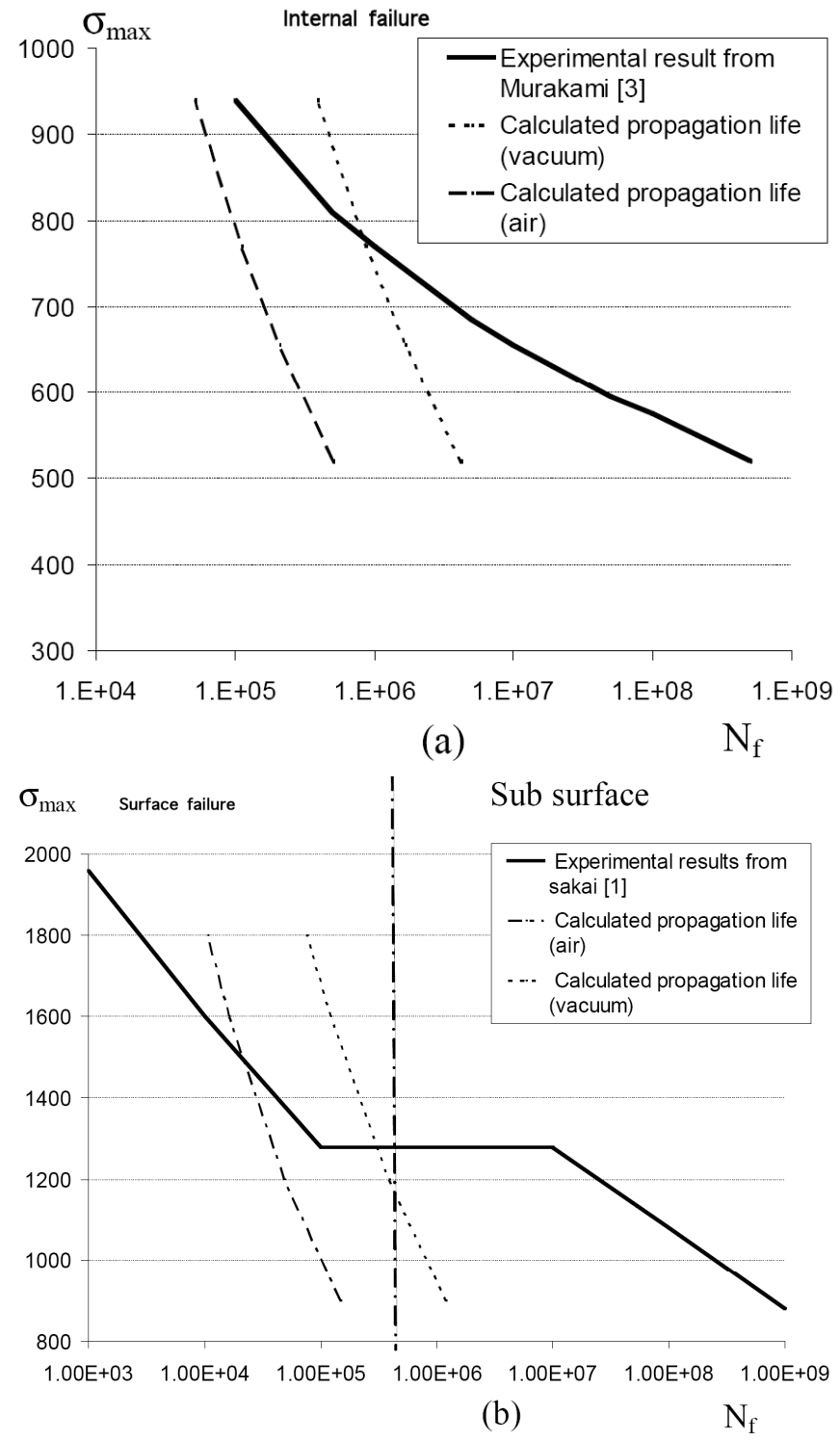

Fig. (4). Calculated propagation life compared to experimental results (a) Murakami, tension, $\mathrm{R}=-1,100 \mathrm{~Hz}$ [3] (b) Sakai, rotating bending, $\mathrm{R}=-1,50 \mathrm{~Hz}$ [1].

Another important parameter is the crack growth law; parameters $\mathrm{C}$ and $\mathrm{m}$ are determined by using general results from Henaff and Petit [18], where an intrinsic effective long crack growth law is determined for various steels under air and vacuum. We have performed some tests to study the sensitivity of the results for the variation of $\mathrm{C}$ and $\mathrm{m}$. Results show that a variation of $10 \%$ on the factor $\mathrm{m}$ for a given stress level of $750 \mathrm{MPa}$, leads to a variation of the propagation life for a factor of two, which is not so important with regard to the effect of the defect size. Factor $\mathrm{C}$ has less influ- ence on the calculated propagation life than factor $\mathrm{m}$. The results show that the variation of $\mathrm{C}$ and $\mathrm{m}$ induces a shift of the calculated propagation curve, but the shape of the curve slightly change. This means that the initiation stage is predominant in the high cycle fatigue range. Compared to the high precision of the experimental determination of $\mathrm{C}$ and $\mathrm{m}$ for a given material, it seems less important than the defect size.

(a)

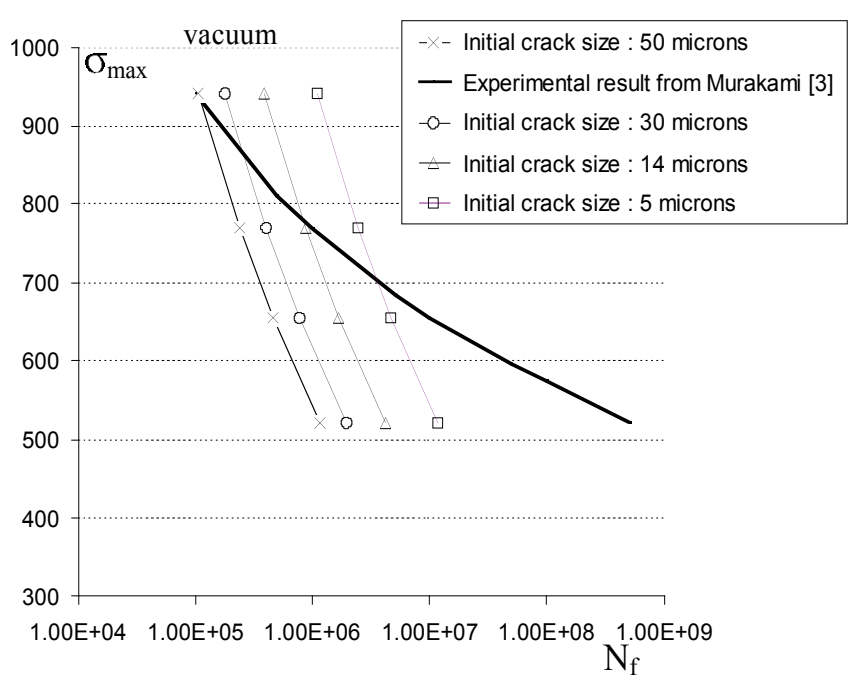

(b)

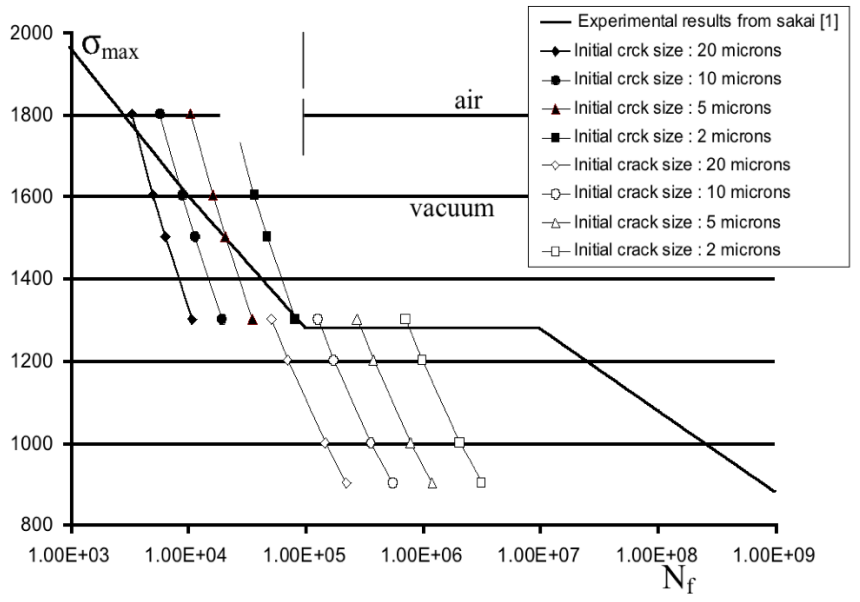

Fig. (5). Influence of initial crack size on calculated propagation life (a) tension, internal defects [3], (b) bending, surface and subsurface defects [1].

In order to simplify the computation, we can integrate analytically the Paris crack growth law to calculate $N_{p}(2)$, which is the number of cycle to propagate a crack between an initial size and the final size to the failure. The integration needs to make the hypothesis that the crack shape factor is constant, so the result is equation (3).

$$
\begin{aligned}
& N_{p}=\int_{a_{i}}^{a_{f}} \frac{1}{C \Delta K_{e f f}^{m}} d a \\
& N_{p}=\frac{2-m}{2}\left(a_{f}^{\frac{2-m}{2}}-a_{i}^{\frac{2-m}{2}}\right) \frac{1}{C(Y \Delta \sigma \sqrt{\Pi})^{m}}
\end{aligned}
$$




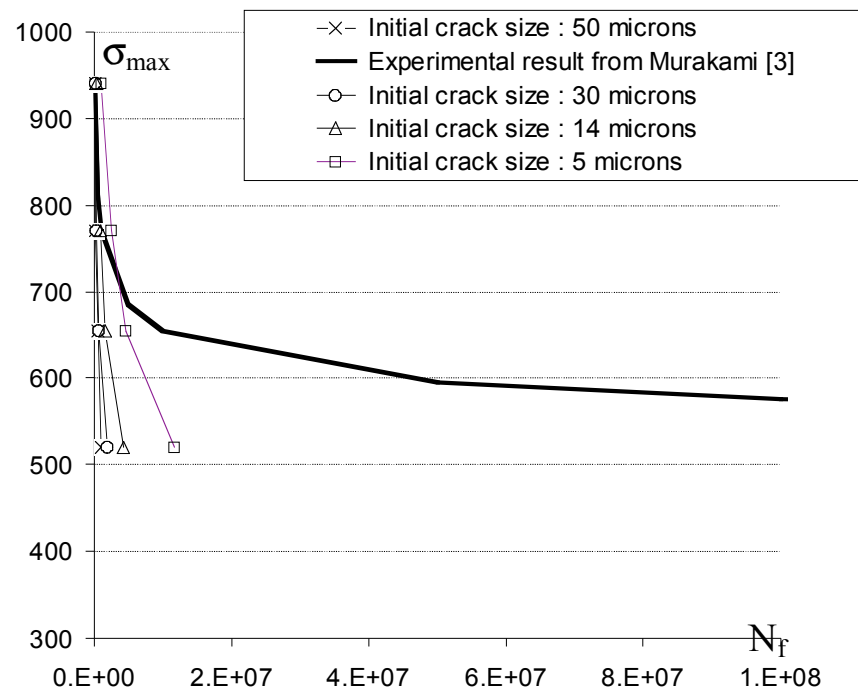

Fig. (6). Influence of initial defect size on calculated propagation life, linear scale.

Comparison between the analytical calculation and numerical simulations is presented in Fig. (7) on Sakai's results, for surface defects. Numerical simulation is an integration cycle calculated by the cycle of Eq. 2, so that it is possible to take into account for real $\mathrm{Y}$ shape factor and it's evolution with the crack depth. The difference between both the calculations is very small and can be neglected as compared to the total fatigue life.

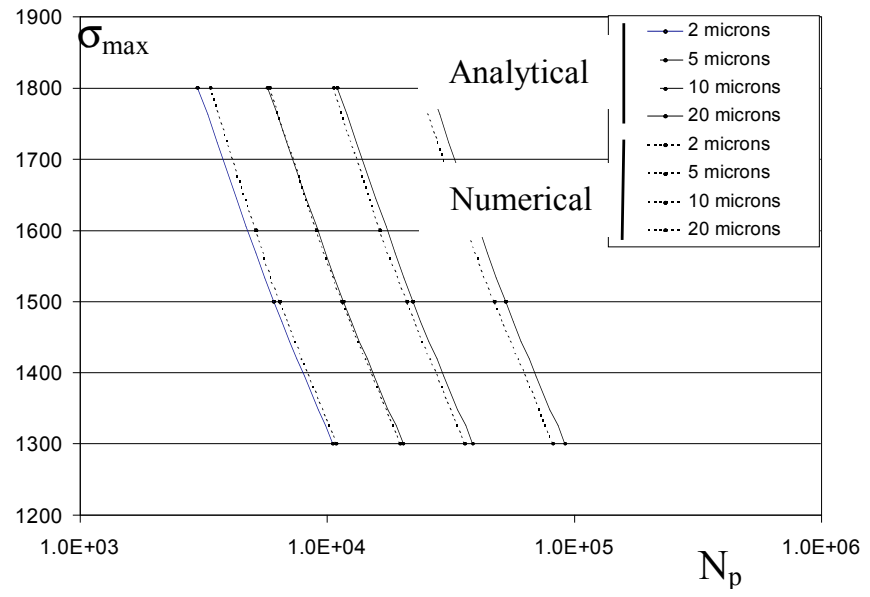

Fig. (7). Comparison between analytical and numerical calculation of propagation life with surface defect.

\section{CONCLUSIONS}

- In case of the fatigue failure due to internal or sub surface defects in the environmental effect, a crack propagation assessment must be taken into account, and an internal defect must be considered under vacuum.
The calculated propagation life, using Linear Elastic Fracture Mechanics, is very sensitive to the initial crack size; a detailed analysis of the defect size population must be performed to give the accurate results. The parameters $\mathrm{C}$ and $\mathrm{m}$ of the Paris law are less influent on the results than the initial crack size.

- The calculation of the propagation life, using an analytical integration of Paris law considering a constant crack shape factor, gives good results.

- When the crack propagation life is correctly calculated (initial defect size, crack shape factor and relevant Paris law), the importance of the initiation stage is revealed in the high cycle regime for either surface or internal initiation. This initiation stage could be described, using a short crack approach, when a detailed experimental data base is available for the defect, considered. Another way is to consider initiation stage governed by the cyclic plasticity at the tip of the defect; elastic-plastic cyclic simulations are required to determine the stress state, at the tip of the defect.

\section{REFERENCES}

[1] Sakai T, Takeda M, Shiosawa K, et al. Proceedings of the $7^{\text {th }}$ International Conference on Fatigue, Congress, Beijing, China, Wu XR, Wang ZG, Ed, 1999; 573-578.

[2] Bathias C, Paris PC. Gigacycle fatigue in mechanical practice, Marcel Dekker, New York, isbn: 2004, 0-8247-2313-9.

[3] Murakami Y, Nomoto T, Ueda T. Fat Fract Eng Mat Struct 1999; 22: 581-590.

[4] Murakami Y, Nomoto T, Ueda T, Murakami Y. Fat Fract Eng Mat Struct 2000; 23: 893-910.

[5] Nishijama S, Kanazawa K. Fat Fract Eng Mat Struct 1999; 22: 601607.

[6] Mughrabi H. Fat Fract Eng Mat Struct 1999; 22: 633-641.

[[7] Mughrabi H. Proceedings of the International Conference on Fatigue in the Very High Cycle Regime. Universitat fur Bodenkultur Wien. Vienna, Austria 2001;35-49.

[8] Miller K J, O’Donnell W J. Fat Fract Eng Mat Struct 1999; 22: 545557.

[9] Mendez J, Mailly S, Villechaise P. Temperature-Fatigue Interaction, Rémy L, Petit J, Ed, ESIS Publication 2002; 29: 95-102.

[10] Nadot Y, Mendez J, Ranganathan N, Béranger AS. Fatigue Fract Engng Mater Struct 1999; 22: 289-300.

[11] Nadot Y, Ranganathan N, Mendez J, Béranger AS. Scr Mater 1997; 37(5): 549-553.

[12] Nadot Y, Mendez J, Ranganathan N. Int J fat 2004; 26: 311-319.

[13] Billaudeau T, Nadot Y, Bezine G. Acta Mater 2004; 52: 3911-3920.

[14] Nadot Y, Denier V. Eng Fail Anal 2004; 11(4) 485-499.

[15] Levan A, Royer J. Int J Fract 1993; 61: 71-99.

[16] Rooke, Cartwright. Compendium of stress intensity factors 1976.

[17] Petit J, De Fouquet J, Henaff G. Handbook of fatigue crack propagation in metallic structures, Carpinteri A, Ed, 1994; 1159-1204.

[18] Henaff G, Petit J. Physicochem Mech Mater 1996; 32 (2): 69-88.

[19] Petit J, Hénaff G, Sarrazin-Baudoux C. Environmentally-assisted fatigue in the gaseous atmosphere. In. Petit J, Scott P, Ed, Comprehensive Structural Integrity, Environmentally Assisted Fracture, Elsevier 2003; 6:211-280. 